\title{
ELECTRICAL RESISTIVITY DATA INTERPRETATION FOR GROUNDWATER DETECTION IN TITTAGUDI TALUK OF CUDDALORE DISTRICT, TAMIL NADU, INDIA
}

\author{
Uwamungu Placide', G.R. Senthil Kumar ${ }^{2}$ \\ ${ }^{1}$ M.Phil Research Scholar, Department of Earth Sciences, Annamalai University, Tamil Nadu, India. \\ ${ }^{2}$ Corresponding Author. Associate Professor, Department of Earth Sciences, Annamalai University, Tamil Nadu, \\ India.
}

\begin{abstract}
The present study aims to detect the groundwater potential in Tittagudi Taluk of Cuddalore District, Tamil Nadu, India using electrical measurement. Electric resistivity data interpretation was carried out using Schlumberger configuration with electrode spacing $(A B / 2)$ of $100 \mathrm{~m}$ distance. The VES was calculated by multiplying the resistance by constant obtained from the Schlumberger formula. The resistivity curves were analysed with curve matching techniques along with the help of computer programme. The sub-surface lithology was evaluated and correlated with the available borehole data. The results of quantitative interpretation of geoelectrical data indicated that the layer system having minimum of two layers to a maximum of eight layers in the area. The low and high resistivities obtained are ranging from 0.5 to $27755 \mathrm{ohm} / \mathrm{m}$ respectively. Majority of resistivity curves are falling in 'A' type. The contact zone of sedimentary and crystalline rock formations are clearly delineated on Northeast to Southwest directions along Sirumangalam, Agaram and Sirumalai habitations. The prominent low resistivity anomaly observed in and around Adari area (VES. 03), this have been encountered in all the iso-resistivity contour maps, indicating that, a trend of structural elements like a weaker zone or lineament or fracture occurred in NE direction of the study area which may be a favorable zone for targeting groundwater.
\end{abstract}

Key words: Electrical Measurements, Tittagudi Taluk, Schulmberger Configuration And Iso-Resistivity Maps.

$* * *$

\section{INTRODUCTION}

The atmosphere and earth's physics is known as geophysics. The investigation of the physical properties of the earth is termed as geophysical exploration and it is used as one of the tool in understanding the groundwater occurrence in the womb of mother earth. Geophysics is highly helpful in assessing the groundwater potentiality of geological formations, estimated weathered zone thickness and bedrock topography, fractures in hard rock terrain, delineate resistive granular zones in sedimentaries and paleochannels and asses quality of groundwater. Geophysical study in groundwater investigation involves two stages; i) deep exploration and ii) shallow exploration. In deeper exploration, the exploring depths beyond the weathered zone of 100 or $200 \mathrm{~m}$ thickness in hard rocks where as in shallow exploration, the exploring depth is 20 to $30 \mathrm{~m}$ thickness. Different authors used different geophysical tools such as resistivity and magnetism for groundwater exploration [1]. One of the geophysical methods employed in the groundwater exploration is the electrical resistivity method. This method is used in groundwater prospecting for its efficiency in detecting the water bearing parameters, and its aerial extension, electrical conduction attributable to pressure of the interstitial water in pores and its chemical quality. This method can differentiate between unsaturated and saturated formation, brackish and saline nature of water. This electrical resistivity method has its ability to determine depth, thickness of the layers and lithology as geo-electrical layers. The resistivity methods are based on the measurement of resistivity of ground after passing an electric current into the Earth. For a metallic conductor, such as a copper rod, the resistance varies directly to the length and inversely to the cross-section and its specific resistance is given by the formulae: $\mathrm{R}=\rho \mathrm{L} / \mathrm{A}(\mathrm{A}=$ area of cross section and $\mathrm{L}=$ length of the rod). The resistivity determined in this case will be true resistivity of copper, if the rod is pure copper metal. In the case of the earth, the conduction is mostly electrolytic. The resistivity determined will be true resistivity, if the ground is homogeneous and isotropic. Usually, the ground is constituted of various materials and there may be some variation in vertical and lateral dimension and the resistivity determined is called as apparent resistivity. In the resistivity method, a known amount of electrical current is sent into the ground by a pair of electrodes and the potentials developed due to current between these electrodes are measured by placing another pair of electrodes present between them. Multiplication of the ratio of the developed potential difference to current input with, geometric factor of electrode configuration gives apparent resistivity of the homogeneous ground.

\section{LOCATION OF THE STUDY AREA}

The present study area Tittagudi Taluk falls in Cuddalore District, Tamil Nadu, S.India (Location map shown in 
Figure 1). The study area lies between the latitudes North $11^{\circ} 22^{\prime} 03$ " to $11^{\circ} 36^{\prime} 29^{\prime \prime}$ and the longitudes East $78^{\circ} 52^{\prime} 42^{\prime \prime}$ to $79^{\circ} 18^{\prime} 59^{\prime \prime}$ in the Survey of India toposheet No. $58 \mathrm{M} / 2$, $58 \mathrm{M} / 3,58 \mathrm{I} / 14$ and $58 \mathrm{I} / 15$. The study area occupies an areal extent of about 615 sq. km and the relief ranges from 62 to $121 \mathrm{~m}$ above MSL. The study area receives an average rainfall of $1100 \mathrm{~mm}$ with more than $80 \%$ of the rainfall received during the $\mathrm{NE}$ monsoon. The minimum and maximum temperature ranges between $20^{\circ} \mathrm{C}$ and $34^{\circ} \mathrm{C}$ in the month of January and May respectively. River Vellar flows in the Southern part of the study area. Geomorphologically the area consists of old flood plains, pediments, duricrust and pediments covered by forest land [2].

\section{GEOLOGY AND HYDROGEOLOGY}

The study area comprises both crystalline and sedimentary formations. The crystalline rock formations comprise $2 / 3^{\text {rd }}$ portion of the study area. The intermediate contact zone is stretching in between these two terrains. The study area rocks belong to early to mid Precambrian period represented by charnockite, charnockitic gneiss, granitoidal gneiss and migmatites indicating the oldest and subjected to granulite facies of metamorphism. The charnockites are intermediate to acid in composition, coarse to medium grained and form the high land topography. The charnockitic rocks are massive to foliate and the foliations usually trending ENEWSW with an average dip of $45^{\circ}$ towards South. The charnockite shows different depth of weathered zone. Eastern part of the study area is occupied by Quaternary formations represented by semi-consolidated sand, sandstone and clays. Inliers of limestone with calcareous clays of cretaceous age are noticed in few locations. In the study area groundwater occurs under water table conditions in the joints, fractures and weathered rocks. Generally, the charnockite of the study area is highly massive and compact and devoid of joints and fractures making it impervious, which in turn result in poor potential. The open wells give better yield than bore wells. Geology map of the study area is shown in Figure 2.

\section{MATERIALS AND METHODOLOGY}

The vertical electrical sounding (VES) measurements were carried out in thirty locations of the study area (Figure 3 ) by using an Indian electronic compensator, Microprocessor based signal stacking digital resistivity meter Model - SSR-
MP-AT-S. The well known Schlumberger configuration of electrode separation spacing $\mathrm{AB} / 2$ of $100 \mathrm{~m}$ as maximum was used for measuring VES.

The resistivity curves of thirty VES locations were analysed and interpreted with the help of curve matching techniques using the Master curves by [3]. The apparent resistivity curves were drawn on the log-log paper and superposed over the particular set of master curves fixed on the hard board. The fitting curve is found by shifting the curve horizontally and vertically parallel to the axis. The values of the resistivity $(\rho)$ and the thickness $(h)$ of the first layer from the graph, and the resistivity of the second bed were calculated. Then combining the resistivities and estimated thickness of the first two layers, a hypothetical single layer, an auxiliary curve is drawn and the lower part of the field curve relating to the larger electrode separation may be matched with the relevant family of theoretical curves. By this means, the resistivity and depth to the third layer may be determined. According to [4] the thickness and resistivities of the second, third and fourth layers determined from the $\rho_{2} / \rho_{1}$, $\rho_{3} / \rho_{1}, \rho_{4} / \rho_{1}$ and $h_{2} / h_{1}, h_{3} / h_{1}$ and $h_{4} / h_{1}$ ratios were given on the type curves.

In the present study, the analytical method was carried out using a computer program RESIST 87 developed by [5] First, the surveyed resistivity data were analyzed manually, and the obtained results of the manual interpretation were used as initial models for the analytical methods required for the computer software. This software program has been used to match the model curve with observed field data. The subsurface lithology was evaluated and correlated with the available borehole data.

\section{RESULT AND DISCUSSION}

There are two types of interpretation methods to analyse the resistivity data. One such method is qualitative method, which include resistivity profiling, iso-resistivity contour and different resistivity curve patterns. Another method is quantitative method based on curve matching method and computerised interpretation methods.

The geoelectrical data is representing the layer system having minimum of two layers to a maximum of eight layers in the area. The minimum and maximum resistivities obtained are ranging from 0.5 to $27755 \mathrm{ohm} / \mathrm{m}$ (Table 1).

Table -1: Geoelectrical data of Tittagudi Taluk

\begin{tabular}{|c|c|c|c|c|c|c|c|c|c|c|c|}
\hline \multirow{2}{*}{ VES No } & \multirow{2}{*}{ VES Location } & \multicolumn{5}{|c|}{ Resistivity (ohm.m) } & \multicolumn{5}{|c|}{ Apparent Resistivity (ohm.m) } \\
\hline & & $\rho 1$ & $\rho 2$ & p3 & $\rho 4$ & $\rho 5$ & $-10 \mathrm{~m}$ & $-20 m$ & $-40 m$ & $-60 m$ & $-80 \mathrm{~m}$ \\
\hline 1 & Ja.Endal & 24 & 90.4 & 517.7 & 517.4 & & 68.05 & 136.5 & 243 & 349.5 & 406.94 \\
\hline 2 & Rettakuruchi & 22.6 & 125.1 & 1711.3 & 326.1 & & 50.45 & 72.28 & 91.54 & 113.46 & 142.5 \\
\hline 3 & Adari & 7.8 & 385.8 & 2775.5 & 93.3 & & 1.5 & 2.25 & 3.64 & 3.86 & 4.78 \\
\hline 4 & S.Naraiyur & 13.3 & 188.5 & 456 & 813.9 & & 51.06 & 87.82 & 176.17 & 261.06 & 294.9 \\
\hline 5 & Sirupakkam & 10.4 & 178.8 & 309.5 & 319.5 & & 37.33 & 79.64 & 124.31 & 159.2 & 244.2 \\
\hline 6 & Kaluthur & 18.2 & 387 & 1012.4 & 117.5 & & 145.33 & 175.62 & 236.95 & 250.37 & 286.08 \\
\hline
\end{tabular}




\begin{tabular}{|c|c|c|c|c|c|c|c|c|c|c|c|}
\hline 7 & Paniyandur & 75.2 & 154.2 & 38.6 & 371.5 & & 55.4 & 100 & 135.5 & $\mid 158.2$ & 168.5 \\
\hline 8 & Mangalur & 75.9 & 471.9 & 714.6 & 1908.2 & & 20 & 39.62 & 74.59 & 88.48 & 110.1 \\
\hline 9 & Pullur & 99.3 & 347.9 & 214 & & & 28 & 38.45 & 68.31 & 108.85 & 142.66 \\
\hline 10 & Sirumangalam & 0.8 & 28.3 & 6.2 & 18.3 & 30.7 & 15.6 & 38.3 & 79.2 & 83.4 & 186.54 \\
\hline 11 & Lakshmanapuram & 45.5 & 76.5 & 97.8 & 281 & 408.1 & 140 & 142.76 & 158.25 & 175.1 & 192.24 \\
\hline 12 & Orangur & 14 & 232.8 & 41.1 & & & 81.17 & 76.04 & 113.9 & 157.79 & 199.25 \\
\hline 13 & Avatti & 8.9 & 264.5 & 226.8 & 339.9 & 355.2 & 119.27 & 175 & 205.75 & 250 & 236 \\
\hline 14 & Agaram & 12 & 98.2 & 202.5 & 468.3 & 1084.9 & 17.05 & 33.28 & 65.1 & 99.26 & 129.86 \\
\hline 15 & Narasigamangalam & 0.8 & 25.3 & 194.6 & 4.5 & 73.1 & 7.8 & 16.4 & 34.8 & 73.25 & 76.8 \\
\hline 16 & Tivalur & 1.2 & 3.9 & 8.4 & & & 1.5 & 1.7 & 2.5 & 2.9 & 3.35 \\
\hline 17 & Meladananur & 4.7 & 112.2 & 183.3 & 594.5 & 183.3 & 114.63 & 169.24 & 265.49 & 274.04 & 265.16 \\
\hline 18 & Melur & 1.4 & 28.1 & 2591.7 & & & 2 & 3 & 5.74 & 7.8 & 12 \\
\hline 19 & Vadakarampundi & 118.9 & 38.3 & 146.5 & 378.3 & 2591 & 53.5 & 64.9 & 93.5 & 123.2 & 162.2 \\
\hline 20 & Thachchur & 2.4 & 82.3 & 929.3 & 101.8 & 675.8 & 56.8 & 75.7 & 112.9 & 99.24 & 93.7 \\
\hline 21 & Adamangalam & 12.9 & 3.9 & 228 & 7.1 & & 8.26 & 8.85 & 16.94 & 25 & 30.05 \\
\hline 22 & Kilnemili & 4.9 & 36.1 & 10.3 & 67.7 & 13.9 & 5.63 & 5.82 & 6.18 & 6.9 & 7.9 \\
\hline 23 & Mosatti & 7.6 & 72.9 & 0.5 & 23.4 & 1 & 10.2 & 17.2 & 19 & 12.7 & 8 \\
\hline 24 & T.Endal & 12 & 251 & & & & 18.43 & 33.56 & 68.88 & 95 & 124.5 \\
\hline 25 & Sirumalai & 8.4 & 18.5 & 2370.8 & 68.3 & 198.6 & 5.5 & 12.22 & 19.35 & 27.74 & 32.7 \\
\hline 26 & Tholudur & 17.2 & 62.8 & 114.6 & 489.2 & 45.4 & 98.52 & 72.6 & 95 & 125.02 & 140.71 \\
\hline 27 & Pennadam & 11.1 & 151.5 & 10.6 & & & 20.96 & 33.97 & 55.68 & 55.3 & 56.05 \\
\hline 28 & Tiitagudi & 17.9 & 99.4 & 2712.8 & 44.2 & & 12.31 & 19.63 & 33.27 & 42.9 & 55.79 \\
\hline 29 & Neyvasal & 17.9 & 89.4 & 712.8 & 44.2 & & 30.01 & 49.05 & 80 & 134.2 & 157.2 \\
\hline 30 & Semberi & 19.3 & 4.7 & 4.1 & 80.8 & 17.3 & 20.99 & 12.99 & 9 & 11.15 & 12.73 \\
\hline
\end{tabular}

\subsection{Qualitative Method}

\subsubsection{Schlumberger Apparent Resistivity Type}

\section{Curves}

The resistivity curve pattern depends upon the electrical conductivity of sub-surface formations. The whole set of three-layer-sounding curves can be divided into four groups, depending on the relative values of $\rho_{1}, \rho_{2}, \rho_{3}$.

1) Minimum type: when $\rho_{1}>\rho_{2}<\rho_{3}$ High - low - high, referred to as $H$ - type.

2) Double ascending type: when $\rho_{1}<\rho_{2}<\rho_{3}$ Low - low - high, known as $A$ - type.

3) Maximum type: $\rho_{1}<\rho_{2}<\rho_{3}$ Low - high - low, known as $K$ - type.

4) Double descending type: when $\rho_{1}>\rho_{2}>\rho_{3}$ High low - low, known as $Q$ - type. The VES resistivity curve types observed in the study area is shown in Table.2.

Table -2: Study area VES curve types

\begin{tabular}{|l|l|l|l|l|l|}
\hline VES No & VES Location & $\begin{array}{l}\text { Curve } \\
\text { types }\end{array}$ & VES No & VES Location & $\begin{array}{l}\text { Curve } \\
\text { types }\end{array}$ \\
\hline 1 & Ja.Endal & AQ & 16 & Tivalur & A \\
\hline 2 & Rettakuruchi & A & 17 & Mel Adananur & A \\
\hline 3 & Adari & A & 18 & Melur & A \\
\hline 4 & S.Naraiyur & AQ & 19 & Vadakaranpundi & A \\
\hline 5 & Sirupakkam & A & 20 & Thachchur & AQ \\
\hline 6 & Kaluthur & A & 21 & Adamangalam & A \\
\hline 7 & Paniyandur & AQ & 22 & Kilnemili & A \\
\hline 8 & Mangalur & A & 23 & Mosatti & AQ \\
\hline
\end{tabular}




\begin{tabular}{|l|l|l|l|l|l|}
\hline 9 & Pullur & AQ & 24 & T.Endal & A \\
\hline 10 & Sirumangalam & A & 25 & Sirumalai & A \\
\hline 11 & Lakshmanapuram & K & 26 & Tholudur & QA \\
\hline 12 & Orangur & A & 27 & Pennadam & K \\
\hline 13 & Avatti & A & 28 & Tiitagudi & A \\
\hline 14 & Agaram & A & 29 & Neyvasal & AQ \\
\hline 15 & Narasingamangalam & A & 30 & Semberi & H \\
\hline
\end{tabular}

\subsection{Iso-Resistivity Maps}

The iso-resistivity values are drawn for the depth of $10 \mathrm{~m}$, $20 \mathrm{~m}, 40 \mathrm{~m}, 60 \mathrm{~m}$ and $80 \mathrm{~m}$ selected along X, Y coordinates of the locations. The iso-resistivity maps are prepared by using surfer software incorporating all the thirty VES data in the study area. These resistivity contours were helpful in delineating the lateral variation in the sub-surface geology of the area. Low resistivity denotes good conductors and high resistivity values are poor conductors.

\subsubsection{Iso-Resistivity At 10 Meter Depth}

The Figure 4 shows the iso-resistivity values at the depth of $10 \mathrm{~m}$. This map mainly represented the top soil zone and to a certain extent of shallow weathered zone. The resistivity value ranges from 1.5 to $145.3 \mathrm{ohm} / \mathrm{m}$. The low resistivity of $50 \Omega \mathrm{m}$ is mainly encountered in the Eastern side of the study area and it generally increases to $100 \Omega \mathrm{m}$ in the Western side. There is a patch of high resistivity zone noticed in and around the Kaludur, Avatti, and Meladanur area. The transition from sedimentary rocks in the Eastern side to hard rock in the West. Northern and Southern parts are represented by variation in resistivity. The good conductive low resistivity are indicative of sedimentary rocks underlined by clay, fine, medium and coarse sands. The poor conductive high resistivities are well marked in the Western and Southwestern parts. The low resistivity zones present on the Eastern and Southern sides are indicative of weathering to certain extent and it is thinning down in central portion of the study area.

\subsubsection{Iso-Resistivity At 20 Meter Depth}

The Figure 5 represents the iso-resistivity values at the depth of $20 \mathrm{~m}$. The resistivity ranges from 1.7 to $175.6 \Omega \mathrm{m}$. The sharp boundary between the sedimentary and hard rock is well illustrated and the low resistivity zone of $0-25 \Omega \mathrm{m}$ is conspicuously absent in the hard rock zone. The charnockitic rocks have shown two distinct types of resistivity zones upto $10 \mathrm{~m}$ depth by the presence of weathered zone and show only uniform range of resistivity upto $20 \mathrm{~m}$ depth with same type of composition in spatial distribution. The high resistivity of more than $100 \Omega \mathrm{m}$ is registered in and around Kaluthur, Avatti, and Meladanur areas. In the Northeastern part of the study area, high resistivity migmatite gneiss is present and within this, a very low resistivity enclave of 10 to $25 \Omega \mathrm{m}$ zone is noted in and around Adari.

\subsubsection{Iso-Resistivity At 40 Meter Depth}

The Figure 6 illustrates the iso-resistivity values at the depth of $40 \mathrm{~m}$, the resistivity ranges from 2.5 to $265.5 \Omega \mathrm{m}$. The high resistivity zone of $100-200 \Omega \mathrm{m}$ found in and around Kaluthur, Avatti, and Meladanur and changed over to the lesser resistivity 10 to $25 \Omega \mathrm{m}$ in the $40 \mathrm{~m}$ depth range. When we go deeper from $20 \mathrm{~m}$ to $40 \mathrm{~m}$ depth vertically, the area around these habitations contains a good conductive zone favourable for targeting aquifers in the charnockite belt of the study area. The very low resistivity zone of Adari is well registered in this particular depth. The high resistivity of 100 to $200 \Omega \mathrm{m}$ range, are prominent in the Northwestern part of the study area. A well-marked moderate resistivity zone of $50-100 \Omega \mathrm{m}$ is represented around VES no. 8 and 2. The slope in the study area is from NNW to SSE, and the elevation is declining towards Tittagudi, Agaram, and Sirumangalam regions. Similar the resistivity is higher on the NNW part of the study area (i.e. Lakshmanapuram, Paniyandur and S. Naraiyur habitations), and gradually decreases towards SSW part (i.e. Avatti, T.Endal, Meladanur and Pullur) habitations.

\subsubsection{Iso-Resistivity At 60 Meter Depth}

The Figure 7 accounts for the iso-resistivity values at the depth of $60 \mathrm{~m}$. The resistivity ranges from 2.9 to $349.5 \Omega \mathrm{m}$. The very high resistivity of 200 to $300 \Omega \mathrm{m}$ is well marked once again, in the places in and around Kaluthur, Avatti and Meladanur. The very high resistivity value of $300 \Omega \mathrm{m}$ is registered near Ja.Endal, on the Northern part of the study area. This high resistivity is uniform and same at the depth of 20 and $40 \mathrm{~m}$. The very high resistivity clearly indicates that the rock types present beneath i.e., migmatite gneiss and the boundary between migmatite gneiss and charnockite portion with lesser resistivity is clearly illustrated by the isoresistivity contours of 20,40 , and $60 \mathrm{~m}$ depth. It noticeably indicates that a weaker zone of structural importance (?) of minor extent is possibly present in that area.

It is evident from the iso resistivity map of $60 \mathrm{~m}$ depth, that the Eastern most part of the study area, where the sedimentary rocks are prevalent and the lithology of the borehole data also indicates the maximum thickness of sediments (clay, fine, medium and coarse sand) which is also clearly indicated with the low resistivity of $25 \Omega \mathrm{m}$. The sediments of moderate thickness are virtually portrayed in the Narasingamangalam, Tivalur, Mosatti, Kilnemeli, Adamangalam, and Semberi areas. The resistivity values below $25 \Omega \mathrm{m}$ in the extreme East-Southeast region, clearly indicates the back swamp deposits of sedimentary origin.

\subsubsection{Iso-Resistivity At 80 Meter Depth}

The Figure 8 exhibits iso-resistivity values at the depth of $80 \mathrm{~m}$. The resistivity ranges from 3.4 to $407 \Omega \mathrm{m}$. The sedimentary portion of the iso-resistivity curves at $80 \mathrm{~m}$ 
shows the similarity of contours at the $60 \mathrm{~m}$ depth. The same is the case with the hard rock area except the Southern most part, where the resistivity range is 50-100 $\Omega \mathrm{m}$. The low resistivity zone encountered at shallow depth of Adari is present once again in this depth without any deviation. The hard massive charnockite with resistivity range of 200- 400 $\Omega \mathrm{m}$ is prevalent in and around Kaluthur, Avatti and Meladanur, habitations. The very same formation also continues around Ja.Endal, Sirupakkam, and S.Naraiyur.

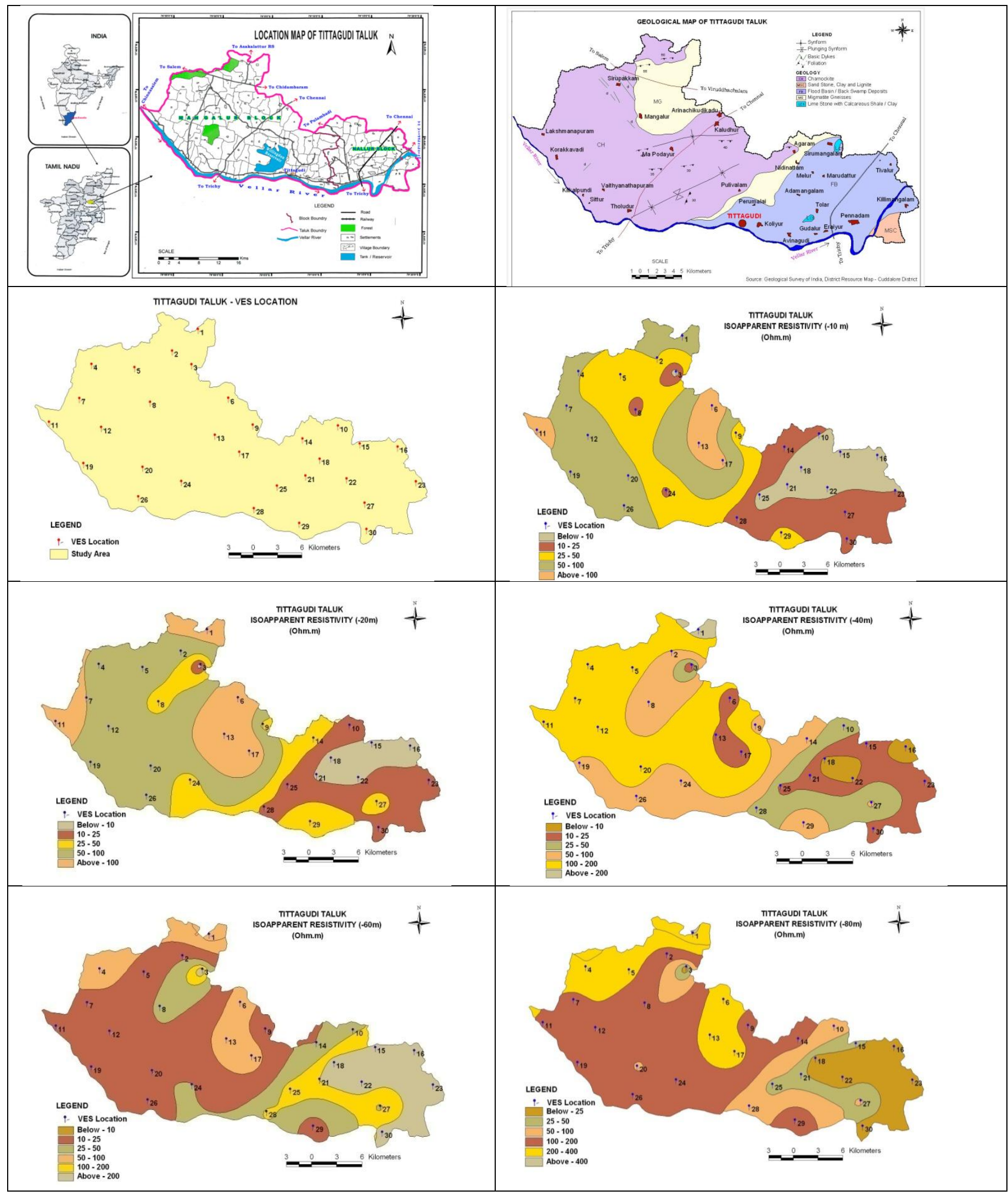




\section{CONCLUSION}

Based on the detailed geophysical investigations in the study area the following deliberations were made:

1. The East, Northeast and Southeast areas are represented by low resistivity contours in the range of 10 to 100 $\Omega \mathrm{m}$, indicating porous sedimentary formations.

2. The West, Northwest and Southwest areas are represented by high resistivity contours in the range of 100 to $400 \Omega \mathrm{m}$ indicating crystalline formations.

3. The contact zone of sedimentary and crystalline rock formations are clearly delineated on Northeast to Southwest directions along Sirumangalam, Agaram and Sirumalai habitations.

4. Majority of resistivity curves are falling in 'A' type.

5. The prominent low resistivity anomalies observed in and around Adari area (VES. 03), have been represented in all the iso-resistivity contour maps, indicating a weaker zone or lineament. (Northeasterly oriented fracture may be a favorable zone for targeting groundwater).

6. Another low resistivity anomaly represented in the regions of Kaluthur (VES .06), Avatti (VES.13) and Meladanur (VES. 17) may be a good fractured zone at a depth of $40 \mathrm{~m}$ bgl sandwitched between two high resistivity layers, indicating a feasible zone for groundwater prospecting.

\section{REFERENCES}

[1]. Sultan, A.S., Mohameden, M.I. and Monteiro Santos, FA. (2009). Hydrogeophysical study of the El Qaa Plain, Sinai, Egypt.Bull Eng Geol Environ, 68, 525537.

[2]. Senthil Kumar, G.R. (2006): Hydrogeological investigations in Tittagudi Taluk, Cuddalore, Tamil Nadu, S. India, unpublished thesis of Annamalai University, pp. 23-27.

[3]. Orellana E. and Mooney H. M. (1972): Two and Three layer master curve and auxillary point diagrams for VES, Interciencia. Madrid, Spain 43pp.

[4]. Sanker Narayana P. K. and K. R. Ramanuja Chary (1967): Short notes - An inverse slope method of determiningabsoluteresistivity, (Geophysics) XXXII (6).

[5]. Karanth K.R. (1997): Groundwater assessment, development and management. Tata McGraw-Hill, New Delhi.

[6]. Vander Velpen (1988) Resist's user's guide. ITC, department of earth resources survey, Netherlands.

\section{BIOGRAPHIES}

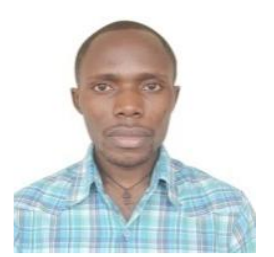

Mr. UWAMUNGU PLACIDE is a M.Phil Research Scholar at the Department of Earth Sciences, Annamalai University, India.

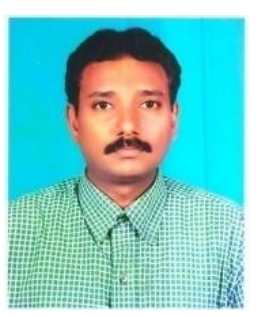

Dr. G.R. SENTHIL KUMAR, Associate Professor, is working at Department of Earth Sciences, Annamalai University since 1999. Speciallized in hydrogeology and Mining Geology subjects. In his credit he has published more than 25 papers in the reputed International Journals. 